\title{
An Analysis on the Selective Translation of Li Sao by David Hinton from the Perspective of Translation Intersubjectivity
}

\author{
Leixin Shen \\ Wuhan University of Science and Technology, Wuhan, China \\ slxin121@163.com
}

Keywords: Negotiation; Selective translation; Translation subjectivity; Translation of $L i$ Sao

\begin{abstract}
This paper analyses Hinton's selective translation of $\mathrm{Li}$ Sao in the light of translation intersubjectivity paradigm. This paper adopts qualitative and descriptive method by analyzing David Hinton's translation of $\mathrm{Li}$ Sao from the aspects of the translator and the author, the translator and the text, the translation and the target reader. A translator is relatively free when he is doing selective translation, since the translator can decide which part he would like to translation. However by the constraints of the author, the text, and the reader, the translator's subjectivity cannot be exerted without limitation. By negotiating with the author and target reader, in the selective translation, the translator remains the finest part that contains the most information about author's intention, and presenting the target readers an acceptable translation. This paper concludes that the translator should bear in mind that selective translation method inevitably spoils the author's intention, the translators should use this method reasonably by never distorting the author's intention.
\end{abstract}

\section{Introduction}

Li Sao is a masterpiece made by Qu Yuan(c.340 to 278 B.C.E), a great patriotic poet of the Chu State during the Warring States Period, and is also renowned for its beautiful diction, truest affection, magnificent imaginations and profound philosophical ideas. Since the British sinologist Edward Harper Parker published The Sadness of Separation, or Li Sao on The China Review: or Notes and Queries on the Far East in 1879, Ch'u Tz'u, or The Songs of Ch'u, began its travel to the western world. Then James Legge's Li Sao, The Li Sao Poem and its Author published in Journal of the Royal Asiatic Society in 1895. Legge's work is basically a rewritten translation. In 1929, Lim Boon Keng, the second president of Amoy University, published the Li Sao, an Elegy on Encountering Sorrows by Shanghai Commercial Press. And many other great western and Chinese translators have made excellent contributions for the cultural transmission of $L i$ Sao or Ch'u Tz'u, such as: Yang Xianyi and Gladys Yang's The Li Sao and Other Poems of Qu Yuan(1953), David Hawkes's Li Sao, On Encountering Sorrow (Li Sao) in Ch'u Tz'u: The Songs of the South(1959/1985), Sun Dayu's Selected Poems of Chü Yuan(1996), Xu Yuanchong's Poetry of the South(1994), Zhuo Zhenying's The Verse of Chu(2006), David Hinton's Classical Chinese Poetry: An Anthology (2008) and Gopal Sukhu's The Shaman and the Heresiarch: A New Interpretation of the Li sao(2012) and so on.

The translation task of $\mathrm{Li}$ Sao is quiet a challenge. The text style is flexible and well-proportioned, with mass allusions and refined Chu dialect. Qu Yuan expressed his deep emotions by metaphor and analogy, symbolizing his ideal politics and noble characteristics by "beauty" and "fragrant flower", and comparing the despicable people to the stinks, endowing short sentences with profound meanings. Therefore, even many native Chinese have difficulty in fully understanding Li Sao.

This paper chose David Hinton's translation of Confronting Grief (the title Hinton translated for $\mathrm{Li}$ $\mathrm{Sao}$ ) as research object, since Hinton made $\mathrm{Li}$ Sao a selective translation of 84 lines in the chapter of THE SONGS OF CH'U (c. $3^{\text {rd }}$ century B.C.E.) in his Classical Chinese Poetry: An Anthology, while the original text is over four times as long: 376 lines. The much shortened version is still of coherence and readability. Then, from the perspective of translation inter-subjectivity, this paper discusses the relationship between translator and author, translator and text, translator and reader, to seek out how Hinton made his selective translation of $\mathrm{Li} \mathrm{Sao}$, and what a standard is for a selective translation. 


\section{Literature Review}

Translation intersubjectivity is a notion adopted from philosophy. There are three philosophical questions that have been discussed for centuries: (1) what do we mean by "being"? (2) how are we conscious? (3) why should I live? Many philosophers were trying to find out the answers of these questions. As a result, their findings have constructed the system of modern philosophy. From Descartes's "Cogito Ergo Sum" (I think, therefore I am), to Heidgger's "Language is the house of Being. In its home man dwells."[1], to Wittgenstein's "the limits of my language means the limits of my world"[2], the philosophers explored for the precise keys to the nature of the world, human's cognitive ability and especially, the significance of language. Habermas's Theory of Communicative Action broke the dualism of subject- object in the study of subjectivity philosophy. Habermas's theory also provided a new idea for translation studies and research approach, for translation is a kind of social communicative action, which involves more than one subject. The limitation of Habermass's theory of Communicative Action is that the communicative action acts under the ethic and moral discipline, and each communicative subject stands in an equal position, which makes the theory quite idealistic. And Bakhtin, too, concerned intersubjectivity and dialogue as the core of his philosophy -Dialogism. Bakhtin hold view that in a dialogue, the participant should keep his outsideness, which means that the independence of subject should be remained. Habermass's and Bakhtin's theory both emphasized the importance of communication/dialogue. Habermass's theory and Bakhtin's theory are of complementarity with each other, shedding great enlightenment on the research of translation intersubjectivity paradigm.

As Chen Daliang concluded that the translator is the translation subject, the author the creative subject, the reader the receptive subject[3]. The translation plays a leading role in intersubjectivity. On the one hand, the translator communicate with the author through the text in order to understand the author's intention and the text's meaning precisely; on the other hand, the translator should negotiate with the target readers, making the translation fit the target reader's expectation.

\section{An Analysis on the Selective Translation of $\mathrm{Li}$ Sao from the Perspective of Translation Intersubjectivity}

Huang Zhonglian classified selective translation as one of the eleven translation variation approaches since he proposed his Translation variation theory. The other ten approaches are: (1)compilation, (2)translation and rewording, (3)contraction, (4)comprehensive rewording translation, (5)rewording translation and comment, (6)translation and comment, (7)remodeling translation, (8)annotation, (9)translation and writing, (10)citation[4]. As Huang points out: "A selective translation is an edition and translation process, which selects the main contents of the original text according to translator's specific needs, or the partial contents that attract the target readers"[4]. The selective translation approach does not take "equivalence" as the rule for translation. A great deal of translator's subjectivity is reflected when the translator extracts the thick into thin and keeps the finer part. Of course, the translator's subjectivity cannot expand without limitation. A qualified translator can never make a deliberate misinterpretation out of context. Translator is endowed with much power by selective translation when he is free to choose which part he would like to translate. The greater the power, the stricter the constraints. Before the translator starts his work of selective translation, the translator must have a full understanding on the original text's overall content and structure, making a reasonable planning for the selection. A successful selective translation is the result of the compromise of each subjects, and eventually reaches a state of harmony.

Translator and Author. Qu Yuan was a poet who lived in ancient Chinese 2000 years ago, while Hinton is a contemporary American translator who has translated many other Chinese classics. There is a huge gap of time and space between Qu Yuan and Hinton. By narrowing the gap, Hinton should know well about Qu Yuan's life and historical background of State of Ch'u, as Hinton noted that:

"Although he is generally considered the first major Chinese poet who can be historically confirmed, little is know about Qu Yuan beyond the legend that he was an adviser of the Chu ruler, 
that he acted with integrity in wisely criticizing the ruler's misguided policies, was exiled, grieved over the damage done to his country by the ruler's actions, and finally drowned himself in the Flood-Gauze (Mi-lo) River as an act of protest." [5]

For Qu Yuan, The ritual suicide at Miluo River was the consequence of his despair by the fall of his birthplace and misery of his fellow countrymen[6]. Hinton must resonate with Qu Yuan's despair and convey it to the target readers. Most translators are convinced that they can do it better than all the others, particularly when it comes to literary and artistic genres[7]. They are, in the first instance, readers, and are subjective as any other readers[7]. As translators, however, they are in a position to formalise their perception and interpretation of a poem in their translation[7]. Despite the fact that Hinton might not share the same life experience with Qu Yuan, Hinton could evoke his emotion by empathy or from the similar life experience. Translator is also a media, matching the target readers' emotional connection with the author. Hinton's understanding to Qu Yuan's life experience was one factor that decided which part of Li Sao Hinton wanted to translate. In Hinton's view, Qu Yuan's life story is the narrative outline of 'Confronting Grief' [5]. So he selected the contents that can mostly reflect Qu Yuan's noble character of patriotism and refusal of being contaminated by evil influences.

Selective translation approach liberates the translator's subjectivity as the translator can exert his creativity by reconstructuring the text, making the translator no longer the author's slave. However, the selective translation definitely spoils author's intention. Much deletion of original text violates the translation ethics that the translator should respect to the author's intention.

Translator and Text. Among the three translation subjects (i.e., the author, the translator and the reader), the text is regarded as the object which needs to be understood. Then, during the process of making selective translation, the translator must have devoted much time and intelligence for selecting the contents that conveys the most information, detaching the part that the target readers are difficult to digest and remaining the best parts of the text.

The content and structure of $L i S a o$ is very complicated. The figures like Nü Xu (which was defined as the name of Qu Yuan's sister by Wang Yi, who was a litterateur in East Han dynasty), Chong Hua (the name of the king Shun, an ancient Emperor of China), Fu Fei (the guardian of the River Luo), Jian Di (the first ancestress of the kings of the Shang dynasty), Er Yao (two daughters of the Lord Youyu), Ling Fen (the Shaman), Wu Xian (the greatest of all the Shaman Ancestors), Peng Xian (an upright minister at the court of the Shang kings, who drowned himself when his good advice was not taken) are keys to promote the plot. A general structure of Li Sao is as follow: an introduction to "my" birth and family background $\rightarrow$ exiled by the king because of "my" honesty $\rightarrow$ Nü Xu's persuasions $\rightarrow$ making "my" plaint to Chong Hua about "my" three times unsuccessful quests for a suitable mate (involving Fu Fei, Jian Di and Er Yao) $\rightarrow$ asking Ling Fen and Wu Xian for divination $\rightarrow$ making a wondrous journey $\rightarrow$ reaching a conclusion that "I" shall join Peng Xian in the place where he dwells.

Hinton's selective translation deleted Nü Xu, Chong Hua, Jian Di, Ling Fen and Wu Xian. So the overall structure of translation is: an introduction to "my" birth and family background $\rightarrow$ being exiled by the king because of "my" honesty $\rightarrow$ stating "my" twice unsuccessful quests for a suitable mate (involving Fu Fei and Er Yao) $\rightarrow$ making a wondrous journey $\rightarrow$ reaching a conclusion that "I" shall join Peng Xian in the place where he dwells. As Edwin Genzler commented: "Bassnett hopes to liberate translators from their slavish attachment to the source text, and empower them with positive imagery"[8]. It means that the translator could exert his translator's subjectivity in the text, rather than making a negative copy to the original text. Hinton noted that Confronting Grief is in fact very long and rather tedious[5], so he created a much shortened version of the original[5]. Hinton abandoned the parts in which he was not interested, while remaining the parts that can mostly express Qu Yuan's noble personality and trace of life, and editing the text in smooth and coherent connections.

However, the deletion has made some loss for the original text. In the original text, Nü Xu's persuasions and "my" asking Ling Fen and Wu Xian for divination expressed "my" dilemma of cherishing "my" moral integrity in the foul world. Without these parts, "my" deep sorrow and anger cannot be fully expressed in Hinton's selective translation. 
Translator and Reader. Readers perceive an end-product, a result of a decision-making process; they do not have access to pathways leading to decisions, to the dilemmas to be resolved by the translator[9]. The translator acts as a bridge by connecting the communication between the author and the target reader. During the process of translation, the translator should communicate with the intentional reader in mind in order to provide a translation that the readers want. The intersubectivity requires that the translator establish a communicative relationship with target readers, as the translator exits to make an effective translation text for readers, while an effective translation text should not only carter to the readers' taste, but also a guidance and enhancement for the readers' appreciation ability. Therefore, whether a translated text can be accepted by the target readers concerns much on the appreciation ability of the target reader and artistic vitality in target language culture.

Although a selective translation text has abandoned some contents of the original text, causing great loss for the author, the quality of the selective translation text might be even better than a complete translation text, since the translator has much time to polish his work. Transcreation is inevitable when translating Chinese poetry to English. Transcreation is a long-established tradition in many cultures that transmits cultural knowledge and values in accessible, exciting, attractive modes to new audiences[10]. The translation of Li Sao is full of rhythm as Hinton adopted utilized the -ing form of words as his transcreation, delivering a phonological charm to the target readers, for example: /scattering ranges/ of /rainbow cloud/ shrouded in shadow/, /jade phoenix-bells/ moaning echoes/ through the sky/. /My team/ of /eight dragons/ writhing and rippling/, /trailing out /pennants and streamers/ of cloud/. The domestication strategy of iambic form makes it easy accepted by English readers. Moreover, the translation form is neat and balance, which meets the readers' aesthetic demands for a poem.

Since there are many culture-loaded words in $\mathrm{Li} \mathrm{Sao,} \mathrm{Hinton} \mathrm{adopted} \mathrm{the} \mathrm{domestication} \mathrm{strategy} \mathrm{in}$ order to make these words intelligible for English readers, as the following table presents:

Table 1 Comparisons of translation

\begin{tabular}{|c|c|c|}
\hline $\begin{array}{l}\text { The culture-loaded } \\
\text { words }\end{array}$ & Meaning in Chinese & Hinton's translation \\
\hline Gao Yang & $\begin{array}{l}\text { Also known as Zhuan Xu, who was } \\
\text { grandson of Huang Di (the 'Yellow } \\
\text { Emperpr') }\end{array}$ & the celestial lord Solaris \\
\hline Bo Yong & The name of Qu Yuan's father & Elder-Constance \\
\hline She Ti & The name of a Chinese constellation & Regent's stars \\
\hline Mengzou & The first month of the year & the prime notch of spring \\
\hline Gengyin & $\begin{array}{l}\text { The fire god's day. The fire god Zhu } \\
\text { Rong was said to be the descendant of } \\
\text { Gao Yang }\end{array}$ & $\begin{array}{l}\text { the day of Solaris's child, the fire } \\
\text { god }\end{array}$ \\
\hline Zheng Ze & "my" familiar name & Resolute Exemplar \\
\hline Ling Jun & "my" formal name & Devine Balance \\
\hline Cangwu & $\begin{array}{l}\text { A place where Emperor Shun was } \\
\text { said to be buried }\end{array}$ & Emperor Shun's ancient tomb \\
\hline Хianpu & $\begin{array}{l}\text { A fairyland on the mythical mountain } \\
\text { of Kun-lun }\end{array}$ & $\begin{array}{l}\text { K'un-lun Mountain's divine } \\
\text { gardens }\end{array}$ \\
\hline Xianchi & The Pool of Heaven & the celestial lake of stars \\
\hline Fusang & In myth, it is a tree in the east where & Solar-Perch Tree \\
\hline
\end{tabular}


Table 1, cont.

\begin{tabular}{|lll|}
\hline Wangshu & $\begin{array}{l}\text { Sun rises } \\
\text { The driver of the moon }\end{array}$ & the moon's charioteer \\
Fenglian & The Wind God & the wind lord \\
Fu Fei & The God masters thunder and rain & the rain lord \\
Qiongshi & A water goddess of the River Luo & the Lo River goddess \\
Weipan & $\begin{array}{l}\text { The name of a mountain located in } \\
\text { Zhangye (northwestern of China) } \\
\text { A name of a river in myth }\end{array}$ & K'un-lun's Thorough-Stone Peak \\
& & \\
\hline \hline
\end{tabular}

According to the table, Hinton's most translations to the culture-loaded words are both faithful to the original meaning in Chinese and comprehensible for English readers. However, as for the names: Gao Yang, Bo Yong, Zheng Ze and Ling Jun. Hinton made some over-translations. Although in Chinese, Yang is much related to the sun, Hinton mistranslated Gao Yang as the celestial lord Solaris, which gives an impression to the reader that Gao Yang is a god who masters the sun. In myth, though, Gao Yang is the Celestial Ruler, it does not mean that he's the master of the sun. And Hinton free translated the names Bo Yong, Zheng Ze and Ling Jun as Elder-Constance, Resolute Exemplar and Devine Balance, though the translations of the names fit the meaning of each Chinese character to some degree. The translations fit neither the western naming style nor the Chinese style, which might confuse the readers who are beginners for learning Chinese. A suggestion for the translation correction is to remain the pin-yin of these names, and making foot note like, Gao Yang: also known as Zhuan Xu, who was grandson of Huang Di (the 'Yellow Emperor'); Bo Yong: Name of Qu Yuan's father; Zheng Ze and Ling Jun: pseudonyms that Qu Yuan named himself in Li Sao.

\section{Summary}

This paper analyzed David Hinton's selective translation of Li Sao from the perspective of translation intersubjectivity. Though, Hinton's translation made a great loss for Qu Yuan the author, as Qu's idea cannot be fully expressed in a selective translation, as for Hinton, on the other hand, the selective translation makes Hinton no longer a slave of the author when he could reconstruct the text in his translation. As for the readers, this is an ear that requires speed and efficiency, a selective translation has the advantage of efficiency which match the times, so that it quickens the culture transmission of the source language in target language. Indeed, the original text of Li Sao is pretty long and obscure. Hinton's selective translation of Li Sao follows the outline of Qu Yuan's life experience, providing the readers an intuitive understanding of Qu's personality and the aesthetic value of the text. This paper also suggests that a negotiation between translator and author, translator and text, translator and target reader is very essential when making selective translation. Though any deletion of the original text spoils the author's intention, the translator must minimize the damage in the selective translation by preserving the finest parts that express the author's intention mostly, meanwhile, the translator must take full consideration on the reader's acceptance and interest. A base line which translator should bear in mind is that selective translation inevitably spoils the author's intention, the translator should adopt this method well by never distorting the author's intention.

\section{References}

[1] M. Heidgger, Pathmarks. Edited by William McNeill, Cambridge: Cambridge University Press, 1998. 
[2] L. Wittgenstein, Tractatus Logico-philosophicus. London: Routledge \& Kegan Paul Ltd, 1955.

[3] Chen Daliang. Who Is the Subject of Translation. Chinese Translators Journal, Vol. 25 (2004) No.2, pp.6-7. (in Chinese)

[4]Huang Zhonglian. The Theory of Translation Variation. Beijing: China Translation \& Publishing Corporation, 2001.pp.124-125. (in Chinese)

[5]D. Hinton, Classical Chinese Poetry: An Anthology. New York: Farrar, Straus and Giroux, 2010, pp. 55-71.

[6] Ye, Lang, Fei, Zhengang, Wang, Tianyou, editors. China: Five Thousand Years of History and Civilization. Hong Kong: City University of Hong Kong Press, 2007, p.206.

[7] V. Pellat, E. Liu. Thinking Chinese Translation. London and New York: Routledge, 2010, p. 155.

[8] S. Bassnett and A. Lefevere, Constructing Cultures: Essays on Literary Translation. Bristol: Multilingual Matters, 1998. p.xix.

[9] Hatim, Basil \& Mason, Ian. Discourse and The Translator. Shanghai: Shanghai Foreign Language Education Press, 2001. p.3.

[10]V. Pellat, E. Liu. Translating Chinese culture: the process of Chinese-English translation. New York: Routledge, 2014, p.96. 